\title{
Separation Fear: An Integral Feature of the Complex Trauma Syndrome in War-Refugees
}

\author{
Vito Zepinic ${ }^{1}$ \\ ${ }^{1}$ PsychClinic P/L., London, UK \\ Correspondence: Vito Zepinic, PsychClinic P/L., London, UK.
}

Received: December 4, 2021

Accepted: January 22, 2022

Online Published: January 26, 2022

doi:10.5539/ijps.v14n1p48

URL: https://doi.org/10.5539/ijps.v14n1p48

\begin{abstract}
Feelings of uncertainty after traumatic event (i.e., forcefully leaving living place) is a common cause of severe fear (anxiety) which may contribute to development of complex trauma syndrome. Traumatic injuries of such depleted individual's sense of aliveness might be quite catastrophic causing a perception that one's identity, togetherness and wholeness is lost forever. In such situation, the individual's response may lead to a cascade of the events which may result in severe symptoms of the hyperarousal, dissociation, depersonalisation, detachment, recollection of the intrusive events, and avoidance of reminder.

Separation fear (anxiety) among war-refugees is a broader condition than it is defined as the anxiety disorder in which dominant features are excessive and inappropriate anxiety of the separation from primary attachment figure(s). In war-refugees, the clinical manifestations are realistic worries about harmful things which may happen to the attachment figure(s) who are left behind - condition of persistent fears for loved ones of being killed, tortured, and possible lost forever.
\end{abstract}

Keywords: separation, fear, anxiety, war-refugees, complex trauma syndrome

\section{Introduction}

Fear of separation from loved ones is very common after traumatic events, such as natural disasters or war trauma, particularly when the periods of separation from loved ones were experienced during the traumatic event (APA, 2013). Since the Bowlby's attachment theory (Bowlby, 1973), separation fear (anxiety) as a phenomenon has mostly been focused upon symptoms relationship in children to the letter development of false alarms related to the traumatic event(s). Thus, the separation fear (anxiety) has occupied as a prominent and exclusive place in many theories of the child development and psychopathology, but less attention has been given to the same features among the adults. Theoretical concept of the separation fear (anxiety) in children purports that an attachment to the others is powerful evolutionary favoured drive with early attachment to a mother figure as the prototype (Barlow, 2002).

However, in war-refugees separation constitutes a part of the trauma syndrome as traumatic event (war) overwhelms the ordinary human adaptations to life and generally involves threats to life or bodily integrity (Zepinic, 2011). Severe trauma (i.e., war, terrorism attack, brutal or repeated rape) impacts the psychic core of the soul of the survivor and generates a search for meaning as to why the event had to happen. The trauma may lead to de-centering of self, loss of groundedness and a sense of sameness, continuity and ego-fragility, leaving scars on one's inner agency of the psyche. In many war-refugees, the fragmentation of ego-identity is a fracture of the soul and spirit of the person, like a broken connection in the person's existential sense of meaning and existence (Courtois \& Ford, 2009; Zepinic, 2010).

War-related trauma, which may also be referred as a complex trauma, is possible the most catastrophic experience in anyone's life regardless of age, gender, culture, religion, etc. It is a complex, multiple and longstanding trauma syndrome which requires very comprehensive and complex approaches in managing and treating the war survivors. The war-related trauma is usually prolonged experience and includes profound disturbance in intra and interpersonal relationships and estrangement from others, pervasive mistrust, hostility and suspiciousness, feeling of emptiness, and altered sense of meaning and purpose of life (Zepinic, 2010). The traumatised war-refugees are overwhelmed by terror and helplessness; their whole life for concerted, coordinated and purposeful activity is smashed; and their attachments could be lost forever. 


\section{Repressed Memories of Complex Trauma}

In clinical practice there is a dilemma: are the traumatic memories too manageable to be narrative or too accurate to be refrained? Clinical cases and studies involving one's recovered memories of severe trauma (i.e., war, torture, rape) have brought some doubts of the veracity of any repressed traumatic memory, and others insist that evident absence of memory proves that a traumatic event(s) occurred. Human memory is a complex process which can be divided into four stages: input (encoding), storage, retrieval, and recounting (recalling). All of these processes can be influenced by the stress and bodily sensations experienced during traumatic event(s), post-trauma managing, and the experience and/or context of the recounting of the event(s). In addition, the retrieval and recounting of a traumatic memory may modify the form of the memory (Zepinic, 2019).

Central to the experience of the refugee's traumatic stress are dimensions of the threat to one's life or loved ones, helplessness, and powerlessness. Forceful separation and migration from home and the community is undoubtedly one of the most serious features of the psychological distress and can affect individual, group of people, or even the entire nation. People affected by the war are under a high threat for their survival, psychological health and social position. Also, due to the war and forceful migration, everything what was built for years - friendships, life targets and values (including properties) - is exposed to devastation and destruction and the trauma survivors experience disbeliefs and fears about their future. It is common in clinical practice to find a broad spectrum of the traumatic memories and broader symptomatology than it is defined in diagnostic criteria of PTSD and stress-related disorders.

The longitudinal course of refugees' trauma syndrome needs to be understood as a multi-staged process which continued after the escape from the war-torn place. This we called trauma-after-trauma phenomenon "experiencing repeated or extreme exposure to aversive details of the traumatic event(s)" - Criterion $\mathrm{A}(4)$ in the DSM-5 (APA, 2013). The most important is to determine one's suffering after escaping from the war-torn place as well as the refugees' predictability and preparedness for the trauma-after-trauma phenomenon (Zepinic, 2019). Apart of real shock because of the war, separation and migration, the development of trauma syndrome associated to the sudden trauma event(s) is usually not an immediate aftermath of the traumatic event, but with its delayed onset.

To be distressed by sudden horror, helplessness and fears is a normal reaction by the humans. However, if this typical pattern for a catastrophic experience, as a response to the event, continues with fear and helplessness (i.e., fear for loved one's safety left in war-torn place), the condition of complex trauma syndrome will likely develop. The most chronic forms of Complex PTSD (WHO, 2018) and other trauma-related disorders represent the failure of healing and modulating the acute traumatic response to the event(s). The nature of this process is a fundamental to understanding the psychopathology of the trauma syndrome. In this concept, traumatic memories play a key role in understanding but also treating complex trauma syndrome (complex PTSD).

Complex PTSD (also called Complex Trauma Syndrome) is a new category in the ICD-11 being distinct from its PTSD-sibling, and other stress-related disorders. According to the ICD-11, the Complex PTSD retains the core PTSD clusters but the ICD-11 added a cluster of Disturbances in Self-Organisation (DSO): (1) problems in individual's affect regulation (i.e., hopelessness, heightened emotional reactivity, feelings of neediness, dejection); (2) altered self-concept (i.e., feelings like failure or worthlessness, incompetence, inadequacy); and (3) impaired interpersonal relations (i.e., difficulties in establishing or sustaining previous interpersonal connections, or avoidance of relationships, isolation, dejection or rejection, ignorance). The ICD-11 taxonomic structure means that an individual can only be diagnosed with PTSD or Complex PTSD, but not both (Zepinic, 2021)

The memories of traumatic experience are an iceberg for the clinicians, the patients, and the researchers. It is worthy to note that forensic clinicians in particular stated that the recovered memory could be even a shield behind which abusers hide as these memories are not always accurate, whereas the false memory is phenomenon of which is question of the therapeutic credentials. On the other hand, it is evident that some trauma survivors are not able to make traumatic memory narrative due to dissociation and which could be only partially accessible, or they simple may not consciously remember the event(s).

For example, during the court proceeding (in case Prosecutor v A. Furundzija) before the International Criminal Tribunal in The Hague, Netherlands, the prosecutor tried to aiding and abetting the brutally repeated severe rapes of a woman by paramilitary soldier accused of committing crime against humanity. The defendant's lawyer suggested that the woman's memory was inaccurate, because it had been adversely affected by her traumatic experience and that the defendant, she identified, in fact was not present at the time when she was interrogated and raped. It is well recognised that dissociation is an aftermath of the severe trauma, and many of symptoms, 
including amnesia, identity confusion and identity alteration, are influenced by the proximity of experienced traumatic event (Zepinic, 2021).

In addition, the processing of trauma experience into the narrative memory is affected by a number of factors, including degree to which it is elaborated, organised, and rehearsed. For example, in case of brutal or repeated rape, trauma victim's cognitive avoidance strategy, due to the stigma, may undermine person's encoding, storage, and/or retrieval of the traumatic experience. However, the confidence in "reported memories" should not be taken as a reliable reflection of the truth of the traumatic memory. For example, raped or tortured person may report accurately details associated with the abuser (face, eyes, smell) but a lower accuracy for other details (such as time, date, or even details about a place where the event occurred).

Extreme trauma usually evokes equally extreme responses and, in the effects to cope and face with a life-threatening, the trauma victim may find her- himself vulnerable to alterations in cognitive, emotional, and neurophysiological responses (van der Kolk et al., 1996) such as psychogenic amnesia, fugue states, and the dissociative identity disorder. Certainly, the war experience, as an extremely traumatic event, causes the most alterations of the trauma-victim's personality with more chronic, ambiguous, and intermittent course.

Although clear clinical evidences support the role of processes to intentional forgetting and thought suppression, it is difficult to find the available evidence to determine when and why such strategies might or might not be proved successful. We do not assume that severe forms of the war trauma are a subject of one's intentional forgetting, but it is rather stored in the person's unconsciousness. Thus, we equally do not assume that there is evidence for a form of the person's unconscious repression of trauma, in which trauma victim became entirely amnesic for periods when severe trauma had occurred.

In our clinical practice while working with war-trauma victims, some patients reported that they attempted to dispel all memory of the war from their minds through their deliberate and conscious effort. They did not like to be reminded of the war experience ("Do not refresh my mind to it") and reported of being able to block thoughts from their minds about it. However, some of them were unable to block their thoughts about traumatic experience not because of their own suffering but because of loved ones left in the war-torn place. So, their separation fear (anxiety) is a constant reminder of the trauma experience, even they do not want it. They simple cannot avoid reminders associated with the own experience but transferred it towards the loved ones who were unable to escape.

\section{Separation Fear in Complex Trauma Syndrome}

Separation fear (anxiety) in refugees who had been forcefully moved from their living place is usually quite excessive or persistent beyond human resilience - it is transient, stress-induced and being persistent. It is typically lasting long after or appear for the first time after escaping from the war-torn place and actual danger or threat. Although there is no a norm or a guide which defines duration that the separation fear (anxiety) is normal reaction, its existence is often chronic and could last even for years.

The common issues are that trauma survivors (war-refugees) are unable to recognise what happened with their (in)ability of realisation and that the trauma caused syndrome of non-realisation. In other words, the complexity of trauma often creates difficulties not only in realisation of the trauma survivor's efficiency but also in daily life (here-and-now) functioning. Refuge condition gives an example of there-and-then functioning (what happens during the traumatic event), and a massively developed separation fear which cannot be seen as the problems of refugees' adaptation to the new environment (here-and-now circumstances). As nobody had been prepared for migration and separation from the loved ones and living place, the refugee status happened under a cloud of severe destruction and loss of lives. There is also a broken connection between the individual and the previous social environment which occurred in an extreme painful way.

Albeit the refugees are desperately in need for security and containment, their frustration about the external world is so real and intense that they may behave aggressively towards the rescuers, even accusing them of making prolonged trauma while taking refuge in the new environment. This regression helps the traumatised individuals to return to the level of a primary process in an attempt to deal with the outer world and the self-image. The self is seen as a purposeless and powerless and the outer world as terrifying and/or threatening. In our own clinical material, the nature of separation fear and anxiety was dominated by clinging to the rejection, reluctance to leave or the dread that something terrible might happen when leaving living place (Zepinic, 2010).

Some studies (Ayalon, 1998; Barlow, 2002; Falicov, 2005; Horowitz, 2001; Wilson, 2006; Zepinic, 1997) suggest that the separation fear in the war-refugees is "mature" expression of the type of distress experienced during the traumatic event(s). The inner threat for survival suddenly changes into a threat from the outside world. 
The world is seen as an enemy and dangerous place which cannot reverse refugees primary traumatic experience into a safe zone. Feelings of disintegration and fragmentation could change one's general sense of the purpose. They defend their strange feelings and perception in finding a lot of strong evidence in the world's horrible reality, cruelty and inhumanity.

These assumptions in self-perception and significant disruption of the assumptive world are actually the inner conflict drives of the trauma that refugees are not aware of it. They see how the outer world being silent about their tragedy and inactive at the time when traumatic event(s) occurred. They developed feeling about the outer world as hostile, dangerous and unpredictable place, unsafe and unstable. The pathology of such perception is a mirrored reflection of the shattered or depleted self, whose continuity and cohesive experience usually have severe break-ups (Zepinic, 2016). Trauma victims may report that their state of the consciousness is fragmented with dramatic perceptual changes in all areas, intense and often with "strange" emotions and with profound alterations in the thought processes. They are experiencing the existence of other perceptions, which are very overwhelming and negative.

We can compare severe traumatisation (i.e., war trauma) as an analogous to a high velocity bullet piercing through the trauma victim's body, tearing apart internal organs critical for survival. Similarly, whereas the brain and heart are critical organs of the body, the self and ego are the core psychic organs for psychological functioning and psychic equilibrium. As the brain and heart are essential structures with interrelated functions, the self and ego are dynamically interrelated in psychological growth, mental health, and well-being. Without meaningful ways to understand traumatic damages to the self by severe trauma, it would be like trying to understand degenerative neurological disorders without understanding how the brain functions (Zepinic, 2010).

Escape from living place due to the war or other traumatic event(s) makes the escapee's feelings of the powerlessness and being unable to change anything to continue any healthy relationships with family, friends or new environment. In our clinical practice, many refugees from war-torn countries reported guilty feelings because for leaving the loved ones behind. They also report concern for safety to those who left there. These symptoms of persecutory anxiety are a striking impact upon already trauma-affected personality. It is not uncommon that refugees who forcefully been removed from the living place feel like guinea pigs for the ethnic cleansing and, also, having feelings they are an island in the world not part of the main (Zepinic, 2011, 2019).

Thus, disintegration and annihilation are often an integral part of the severely traumatised individual's shattered self, which is unable to accept anything else real, but the danger and uncertainty. Everything in the refugee's past, including primary traumatic experience, seems invalid, unreal, unimportant and ineffective. On the other hand, the new environment may be seen as dangerous and unpredictable, which is result of the refugee's discontinuity of the inner world which is transferred into the outer world. Due to length of trauma experiences, this condition cannot be seen as a normal response to the abnormal occurrences. In severely traumatised individuals, their shattered self is real and existing, and everything previously being normal then turned out into a severe non-adaptiveness.

Fear is an emotional response to a real or perceived threat; it is often accompanied with an anticipation for a future threat what is typical in refugees separated from loved ones who are left in the war-torn place. In clinical practice these two states overlap, although could be separated, and it is often difficult to make distinction between them. The DSM-5 (APA, 2013) defines that the fear is mostly associated with the surges of an autonomic arousal necessary for fight or flight, thoughts of the immediate danger and escape behaviours. The fear and/or anxiety is more often associated with a muscle tension and vigilance in preparation for the future danger and cautions, or the avoidant behaviours. The DSM-5 (APA, 2013) defines separation anxiety disorder as an independent entity and diagnoses it as follow:

A. Developmentally inappropriate and excessive fear or anxiety concerning separation from those to whom the individual is attached, as evidenced by the least three of the following:

1) Recurrent excessive distress when anticipating or experiencing separation from home or from major attachment figures;

2) Persistent and excessive worry about losing major attachment figures or about possible harm to them, such as illness, injury, disaster or death;

3) Persistent and excessive worry about experiencing an untoward event (i.e., getting lost, being kidnapped, having an accident, becoming ill) that causes separation from a major attachment figure;

4) Persistent reluctance or refusal to go out, away from the home, to school, to work or elsewhere because of fear or separation; 
5) Persistent and excessive fear of or reluctance about being alone or without major attachment figures at home or in other settings;

6) Persistent reluctance or refusal to sleep away from home or to go sleep without being near a major attachment figure;

7) Repeated nightmares involving the theme of separation;

8) Repeated complaints of physical symptoms (i.e., headaches, stomach-aches, nausea, vomiting) when separation from major attachment figures occurs or is anticipated.

\subsection{Separation Fear in Adult Refugees}

Separation fear (anxiety) is mostly associated to the children; however, in case of the war-refugees, numerous studies (Zepinic, 1997; Despotovic, 1997; Simic \& Srna, 1997; Garland, 1998; Courtois \& Ford, 2009; Duckworth \& Follette, 2012) revealed that adults suffer more severe fear than children for loved ones left behind. Regarding separation fear, the clinicians are in a puzzle where is red line between the separation fear as disorder and real fear for apparent or anticipated danger for loved ones left behind in the war-torn place. In situation when one's life had been under threat to survive it is common aftermath that the trauma victims overestimate their and others danger in post-trauma time. Those who work with the war-refugees should evaluate trauma victim's fear (anxiety) which is often quite excessive and out of proportion.

The vast majority of our patients (war-refugees) who have suffered from complex trauma syndrome complained of having persistent nightmares and bad dreams (Zepinic, 1997). Their dreams were coloured with themes of leaving living place and some of their loved ones stayed in the war-torn places with real risk of being killed, injured, or traumatised otherwise. Their symptoms were long-lasting (some have symptoms for few years) Criterion $B$ of the PTSD diagnosis under the DSM-5 (APA, 2013). Before being referred for psychiatric therapy, some patients spent several months visiting other specialists (i.e., neurologist, endocrinologist, cardiologist) due to their physical symptoms with no found any physical reasons for such condition (nausea, headaches, vertigo, vomiting, sweating, hot flashes, shortness of breath, heart palpitation).

The DSM-5 (APA, 2013) describes that the essential feature of separation anxiety is an excessive fear or anxiety concerning separation from home, loved place or attachment figures. However, such condition is, in fact, part of the cluster symptoms in trauma syndrome and even excessive or unrealistic fear cannot be ignored in the victims of trauma, otherwise the patients are under a high risk of developing severe helplessness with possibility that the trauma syndrome symptoms would further deteriorate. Even more, the separation fear may cause the panic attack as a result of an excessive fear related to loved one who is still under the evident danger or threat (Zepinic, 2018).

Sadly, such panic attack is usually expected as the aftermath of an abrupt surge of intense fear which is often accompanied by physical and/or cognitive symptoms (forgetfulness, short-term memory impairment, confusion and lack in orientation). Some reports suggest that the panic attacks seen in victims of trauma could be a "mature" expression of the type of some distress (Barlow, 2002). Klein \& Rabkin (1981) hypothesised that "spontaneous" panic attacks might be an expression of a "protest-despair" mechanism contingent of threats of separation in those with a biologically determined lowered threshold to this response.

Trauma victims often have persistent and excessive fear or reluctancy about of being alone, going away from the living place, or refuse to go outside without a trusted companion, have excessive worries or concerns about having an illness, and feel detached from their previous relationships. Individuals with separation fear experience recurrent excessive distress when separation from home or major attachment figures is anticipated or occurs. They worry about loved one's well-being and survival, but they also experience fear about harm or death of the attachment figures.

It is well-known that any separation from loved ones by force is very painful and traumatic and those who are separated want to know the whereabouts of their attachment figures and, often, they wanted to stay with them whatever happened (Despotovic, 1997). Also, forcefully separated persons are worried about untoward events to themselves, such as getting lost, being kidnapped or having an accident. Further, they experience fear that, when separated, there are no possibility even being reunited with their major attachment figures.

Indeed, distress regarding separation from loved ones or other familiar persons is common psychological symptom familiar to person who suffers from trauma syndrome. It may even be regarded as a normal corollary of the interpersonal detachment. In case of severe trauma, the separation fear could be prolonged and causing clinically significant distress or functional impairment that the diagnosis of separation anxiety disorder is warranted. Trauma syndrome patient may experience uncertainty and feel uncomfortable when travelling 
independently (i.e., sleeping in the hotel or other organised accommodation for the refugees). Separated from attachment figure(s) or loved ones, individual may report repeated nightmares in which the content expresses the individual's separation anxiety disorder (i.e., destruction of the family due to the disaster or some catastrophe).

These circumstances may increase frequency and severity of the nightmares and more likely experience of the flashbacks. The nightmares are related to the patient's fear of separation (i.e., tragedy in family during some disaster, torture, murder). Alongside with the nightmares, patient may also complain of the broadly different physical symptoms (i.e., abdominal pains, muscle spasm, hypertension, severe headaches, nausea), or the cardiovascular symptoms (i.e., dizziness, heart palpitations, and feeling faint) (Despotovic, 1997; Zepinic, 1997).

The DSM-5 (APA, 2013) recognises that an adult individual could be diagnosed with separation anxiety disorder if fear, anxiety or avoidance are persistent and last six or more months. In complex trauma syndrome, which is commonly a long-lasting condition, these symptoms are quite evident, in particular among the youth (children and adolescents) who could be diagnosed with separation anxiety disorders if their symptoms exist four or more weeks. Adult refugees usually have an excessive fear concerning separation from those to whom they are attached anticipating danger or threat for attachment figure(s). It is expected persistent and excessive worries about possibility of losing loved ones; they could be harmed or even dead. Worries are also related to the possibility that those left behind could be exposed to the torture because of relationships with those who escaped from the war-torn place.

Those who suffer separation fear due to the excessive worries for loved ones, usually suffer distress or impairment in social, emotional, and other areas of functioning. Clinicians are united in opinion that separation fear in war-refugees may occur before or after the life stress, especially if patient suffered some losses (i.e., attachment figure, close relative or friend, a move to new environment, immigration (trauma-after-trauma phenomenon)), or disaster which involves periods of separation from attachment figures.

According to the DSM-5 (APA, 2013), the essential features of the adults' separation anxiety disorder is an excessive fear concerning separation from the living place and/or attachment figures. They worry about well-being or death of the attachment figures because of being forcefully separated from them, and they want to know about condition of their attachment figures. The war-trauma victims also worry about untoward events to themselves for an uncertain future, loss of the self-strength, vulnerability and possible re-experiencing trauma. Severely traumatised individuals are reluctant to accept that the world is a safe place and that their fear could be related for anticipated horror that they already have experienced (Herman, 1992, Horowitz, 2001; Zepinic, 1997; Zlotnick et al., 1999).

Many refugees also report condition of a guilty feeling because of leaving the loved ones, relatives or friends, behind while violence or horror is not over in the places from where they come. These symptoms of guilty feelings associated with the separation fear and anxiety are striking impact upon the severely traumatised individuals. Although separation fear and anxiety are diagnostically more related to the children than to the adults, with refugees it occurs evidently more in adults than in children. Separation fear for the family is tied to one's previous traumatic experiences which may manifest through the intrusive thoughts and the flashbacks related to family members who remain living in dangerous condition (Miller et al., 2018).

Adults with separation fear are typically overconcerned about their offspring and spouses, and may experience marked discomfort when they are separated from them. They may also experience significant disruption in work or social relationships because of their needing to continuously check on the whereabouts of a significant other. A person feels vulnerable if he/she believes that he/she does not have ability nor important (survival) skills to cope with a particular threat (Zepinic, 2015). Due to this feeling, many difficulties may turn into further threat (i.e., suicidal behaviour) when trauma victim realises that he/she does not have the minimal survival skills to resolve problem with serious ramification.

This is quite common with the refugees who face many inexperienced particulars such as unfamiliarity with a foreign language, or they face the problem in communicating with other people in the host country. They feel helpless in obtaining any support if they, for example, feel lost or become ill. This can cause one's self-doubts and a sense of weakness or even total incapacity what may lead to the seriously depleted trauma victim's self-confidence. There is consistency between cognitive and somatic manifestations of the vulnerability as trauma victim finds it is difficult to be objective about the own self-appraisals. Furthermore, the ability to gain an overall perspective of immediate difficulties is usually undermined. Trauma victim sees an error in an absolute term and finds it is difficult to view it in the total context; he/she thinks as only failure counts, success does not offset it at all. 
Such individuals who lack in confidence may have a cognitive set of helplessness and tend to feel passive, weak and "mushy", and may experience tension or muscle spasm (Beck et al., 2005). In vast majority of the trauma victims, we can recognise that their self-confidence is diminished. The self-confidence is defined as the individual's positive appraisal of assets and resources in order to master problems and deal with the threats. Pathological loss of self-confidence inevitable leads to the development of depression which could be associated with suicidal behaviour. Those who lost self-confidence lose with reality and relapse to a trauma experience; the person loses the distinction between the own personality and the environment (reality). A positive self-confidence gives to the person a sense of self-efficiency - positive subjective feeling.

In our clinical experience we found that this condition in refugees may also display itself in the form of excessive homesickness and losses, inability to have family together or any other situation which threatens to separate refugees from their living place, motherland, relatives and friends. They feel unable to rebuild something on positive level and even any success they see not having permanent effect because the "vulnerable" person believes that may always slip in the future, and that the consequences of the slip will be far more drastic than any success could be. Because of their traumatic past, the trauma victims apparently have greater access to negative memories of the previous performances than to the positive one.

Fundamentally, the separation fear can always be traced to one's disturbed homeostasis and the refugee-motherland relationship. In a state of vulnerability, the trauma victims have a selective recall which appear to be function of the "vulnerability mode" and more likely being influenced by the past (there-and-then) events suggesting the flaws and dangers which are relevant factors to the posttraumatic growth (here-and-now circumstances). The person finds it is difficult to be objective about own negative self-appraisals, even if person tries to succeed with a needed and received help from others.

There is a general agreement among clinicians that separation fear occurs when person is directly threatened with a dangerous, perhaps the life-threatening event (Barlow, 2002). Fear represents basic, fundamental, discrete emotion which is universal regardless of one's age, gender, or culture. Whether innate or not, it is universal and has a clear functional value in one's behaviour and in expressing emotions. Fear is an outcome of already stressful condition which is often uncontrollable and realistic, albeit the real danger is over.

Fears may cause further distress/sadness, anger, shame and guilt. There are numerous signs which characterised the person's condition under the intense fear: afraid, apprehensive, ashamed, confused, desperate, indecisive, horrified, insecure, pressured, scared, self-destructive, terrified, vulnerable, ... to name just some of them. Fear is inevitable associated with the person's changes in the cognitive functioning and decision making about situational factors. It is contrasted with real fear associated with some real object or situation in the environment. Such fear may cause avoidant disorder characterised by pathological shyness which interferes with the peers functioning, persistent shrinking from contact with strangers, or overanxious disorder characterised by generalised persistent worrying about the future, excessive need for reassurance, or multiple unfounded somatic complaints.

The fear in the trauma victims is an "alarm" that dangerous situation is present (even only in mind) and the person's apprehension is clearly evident. Under this condition, the emotion of fear mobilises person, physically and cognitively, for a quick action and sometimes could be an extreme effort. Most typical for the trauma victim is an attempt to escape from traumatic event as the threat is apparent and this represents emergency reaction characterised by the compelling action tendencies of the flight or fight. Sometimes these actions can be even counterproductive as the individual, overwhelmed by fear, cannot respond rationally. In some extreme cases, the fear produces reactions of freezing response; the person is ineffective and not available to react. Most theorists would agree that the freezing response is a primitive alarm reaction - it is, however, a state of inability to use any mental capacity to respond.

However, separation fear among refugees needs more studies instead of approach such as it is a problem which is inevitable present and does not need to be investigated further. Thus, separation fear is characterised by an abnormal reactivity to the real and forceful separation and significantly interferes with one's personality functioning. It causes marked impairment and distress, can lead to the several negative psychological outcomes and it is predictive of the other psychiatric disorders, in particular complex trauma syndrome (complex PTSD). In spite of this, the problems related with separation during distress are seldom investigated, in particular among the war-caused refugees and orphaned children.

How incompetent approach towards the refugee children and their parents could be, even by some officials, it is probably typical example during civil war in Yugoslavia (1991-1996). When ethnic conflict started, in Sarajevo was established the UN Children Embassy which official employees were holding the UN passports and fully 
protected by the UN Blue Helmets (the peacekeepers). Although crisis escalated quite quickly with no control and mostly being run fighting by the paramilitary militias, the Embassy established its offices in the elite building in the city centre and was supplied with the luxury vehicles and furniture. The Embassy's employees were able to travel freely through the conflict zones escorted by the UN Blue Helmets. It was interesting that Embassy employees were able to travel outside sieged city (Sarajevo) and war-torn country (Bosnia \& Herzegovina) having the UN passports and they regularly received a high salary and enjoyed life in the city under siege.

The Embassy quickly admitted the voluntary members mostly well-respected individuals (academics, celebrities, sporting legends, etc.). The main activity of the Embassy was to evacuate children from the surrounded Sarajevo and send them to the Western European countries and further, but without a company of the parents or any family member. It is estimated that around 3,500 children were evacuated from Bosnia \& Herzegovina by the busses and resettled somewhere, but no proper information about the places of settlement was ever given to their parents. Sarajevo was under siege for 1,425 days (from 5 April 1992 until 29 February 1996) and no ordinary citizens could escape without risk of being killed by a sniper, or grenades.

When the peace agreement was signed (Dayton Peace Accord in December 1995), many parents (who survived) tried but could not find information about their children as the UN Children Embassy closed its offices and evacuated employees giving them the entry visas to any country they wanted to go (of course, without needed regular procedures of the immigration). However, we can only imagine the parents' and children's pain and grief caused by the "humanitarian action" what the UN Children Embassy done separating children from their parents, or sibling from sibling. Certainly, it is serious question what happened mentally with the children (orphans) whose parent were killed during war and nobody was looking for them. Study (Whetten et al., 2010) suggests that potentially traumatic experiences of the orphaned and abandoned children are all at risk for additional potentially traumatic events.

\subsection{Separation Fear in Refugee Children}

In case of war-refugees, children seek to avoid separation from their parents, their sibling(s) or attachment figure, or even to eat without the attachment figures being present. They have persistent and excessive fear or reluctancy of being alone with unknown person(s). Children may express persistent fears that they will become permanently (even forcefully) separated from the attachment figures (being orphans), particularly by some calamitous event such as war, killed or injured attachment figure, disappearance of the attachment figure, or in the case of severe natural disaster. War-affected children experience significant distress when separated from the attachment figures and may spend most of the time crying and asking reunion.

As calamitous event(s) usually delivers imminent separation, children may display signs of an extremely subjective distress, terror and autonomic symptoms of anxiety or panic attacks such as palpitations and hyperventilation, shortness of breath, trembling, shaking, severe sleep disturbances or nightmares, and actively resist separation. Their resistance may take the forms of tenaciously clinging to attachment figure(s), and/or screaming, crying, begging or complaining of having some severe somatic distress or illness, most often in the form of abdominal pain (Black, 1995). Children with separation anxiety may be unable to stay or to go in a room alone by themselves and may display "clinging" behaviour, staying close to or "shadowing" the parent(s), or requiring someone known to them being with them when they go to the bedroom.

In our clinical practice while working with the refugees, there were numerous cases to suggest that forced separation caused development of a significant distress and severe mental health disorders in children. Fogden et al. (2020), in a study of the impact of family separation, found among refugees the evidence to suggest that stress or worry about separated family members contributed to posttraumatic stress symptoms or levels of psychological distress on children. Upon separation from the attachment figures (usually parents) and home, children may develop excessively persistent fears or worries about their future but also worries that something may happen to their parents or other attachment figures; they suffer behavioural (crying, clinging, searching for the parents or sibling after their departure), and/or somatic symptoms such as headaches, abdominal pain, fainting spells, dizziness, light-headedness, chest pain, etc.

Needless to say, the fear and anxiety symptoms upon separation from the parents or major attachment figure(s) are developmentally normal in children, and distress about separation from the attachment figure in infants is one of the most strongly preserved evolutionary behaviour (Shear et al., 2006). Longitudinal studies suggest that, due to the separation from attachment figures (mostly from the parents), child is in a high risk for developing other severe mental health disorders; it specifically increases the risk for a panic disorder and agoraphobia in female adults, mainly due to their similar clinical presentation (Gittelman \& Klein, 1985). 
Gittelman \& Klein (1985) reported that the anxiety and agoraphobia in women due to the separation in childhood may simply reflect the early expression of a generalised gender-specific method coping with stress and anxiety. Approximately one-third of separation anxiety problems from childhood persist in the adulthood if untreated. Also, children through the childhood, and letter in the adolescence, may significantly limit their interactions with peers, which may lead to a severe impairment in social functioning and isolation in adulthood (Shear et al., 2006).

The separation fear and anxiety are quite evident conditions in refugee children; they have persistent and excessive fear or reluctance about being alone or without major attachment figures such as parent(s), older sibling, family member, etc. It is common that upon their resettlement, they experience resistance to go to school and often suffer psychosomatic symptoms due to their separation (diarrhoea, headaches, dizziness). They are afraid of being or staying alone at unknown place with strangers - they are usually unable to establish proper attachment and trust to another attachment figure(s).

In war-refugees, the parents often report that their children are not able to stay or to go in a room by themselves and they display "clinging behaviour", staying close to or "shadowing" parents around the house or require to be with them when going to another room in the house. However, the most common reasons for parents to seek treatment is the child's school absenteeism and frequent complaints of somatic symptoms which generally have no physical origin. School absenteeism is characterised by the presence of fear of rejection or an anger vis-à-vis participation in school, combined with a strong sense of guilt concerning itself and concomitant conflict life withdrawal into the home.

It is almost common that refugee children with separation fear refuse to sleep in a separate room and insist to sleep with parents and, despite of reassurance by parents that no danger exists, they will still be resistant to sleep separately. If they accept to sleep in separate room, they will insist that someone stay with them until they fall asleep. However, as their sleep is usually followed by the nightmares which woke them up, they will make their way to their parents' bedroom. Also, children may be reluctant or refuse to attend camp, to sleep at the friends' home or to go on errands (APA, 2013).

In children, there could be repeated nightmares in which the content expressed the child's separation (leaving living place or destruction of the family through the escape). Physical symptoms such as headaches, abdominal complaints, nausea, vomiting, muscle cramps, etc., are related to the fears with no evident physical condition. Cardiovascular symptoms such as palpitations, dizziness and feeling faint are rare in very young children but can occur after in adolescence period and being subject of bullying by other children.

Due to the forceful separation, children may develop total or selective mutism: consistent failure to speak in social situations before the strangers or places that could be associated with the place and circumstances which reminds of painful separation. Victim's lack of speech occurs in social interactions with others could be an unconscious reminder that "the outer world is an unsafe place". The disturbances are often marked by a high social anxiety and mutism may occur even with close family members or friend while talking about traumatic event(s). Mutism as a common aftermath of the severe trauma is well-known phenomenon since for the first time being described as a symptom of the shell shock (Myers, 1916).

Children with mutism due to the forceful separation often refuse to speak at school, leading them to academic or educational impairment, as teachers are not familiar with background of the disorder. Their luck of speech may also interfere in social relationships with other children, apathy and isolation, the signs of severe depression which may lead to the child's suicidal behaviour. On the other hand, children with the stress-related mutism may willingly involve in non-verbal communications with other children or engage in social encounters when speech is not required (i.e., non-verbal parts in school play or sport activities).

Clinical features with the mutism include an excessive shyness, clinging, fear of the social embarrassment, loneliness, social isolation and withdrawal, compulsive traits, negativism, temper tantrums or oppositional defiant behaviour. With mutism caused by severe stress, it is important to know that there is nothing neurologically wrong in the child's development. Clinical assessment usually reveals a highly evident level of anxiety which almost always lead to additional diagnosis of another anxiety disorder - most commonly social anxiety disorder or social phobia.

Due to shocking forceful separation and witnessing horrors of war, children may develop a high level of specific phobias - marked fear of flying or travelling in a bus, fear of animals, or seeing blood. They may manifest their fear in the forms of unreasonable crying, tantrums, freezing, and any object or situation that remands of the separation circumstances provokes an immediate fear or severe panic. The fear is out of proportion to the actual danger posed by a specific object or situation. However, the fear and anxiety are usually chronic and long-lasting 
after the traumatic event had been experienced. An intense fear or avoidance of the object or situation may cause significant distress or impairment in child's social, emotional and other important areas of functioning, particularly in academic impairment.

A key feature of specific phobia is that the fear is circumscribed to the presence of a particular situation, object or place which is the phobic stimulus for excessive reactions. Many theorists in stress disorders define particular stimulus as a trigger factor which reminds of the particular stress experience. However, in some cases only under the expert assessment this matter is recognised as associated to the past trauma experience, otherwise it has been unrecognisable by the trauma victim. The fact is that the specific phobia is specific itself and the response differs from the normal, transient fear commonly occurs. Specific phobia caused by shocking traumatic experience also differs from other types of phobias as it is provoked only by a trigger which reminds of the trauma experience in the past, and it is commonly more intense or more severe.

The amount of phobia may vary with proximity of the anticipated stimulus as more stimulus is authentic more severe fears will occur with possibility leading to the panic attack. Another difference from ordinary types of phobias is that, in specific phobia, the fear or anxiety is evoked every time the traumatised child comes into contact with the stimulus. The degree of fear or anxiety may vary (from anticipatory fear to a full panic attack) but do not disappear in the presence of an alternative attachment figure's presence. Because of various contextual factors (i.e., persons in uniforms who are holding guns) the child who suffers specific phobia may collapse or being hysterical when face with stimulus and usually will be neurologically investigated instead of assessing the child's affected psychic equilibrium.

With specific phobia caused by severe stress due to separation, the child (or the parents) is not aware of which situation, place or person should be avoided. Unlike in other phobias, this phobic condition does not "instruct" patient of an active avoidance as sufferer is not aware of the inner drives which cause intense fear or panic. Thus, the child is not aware of ways to prevent contact with the stimulus that may cause phobic reactions. Unlike in other phobias, child is not able to identify what is needed to avoid as different stimulus may cause fear and phobic reactions. Without specific stimulus, the child does not show any fear or anxiety of a similar object at different place or similar place but without object stimulus.

Separation fear in refugee children may also be associated with an increased risk for suicide. In a community sample, the presence of mood disorder, anxiety disorders, or substance abuse has been associated with suicidal ideation and attempts. When separated from attachment figure (in particular from parents), children may exhibit social withdrawal, apathy, sadness or difficulty concentrating and forgetfulness. Depending on their age, they may have fears of the animals, monsters, darkness, muggers, burglars, kidnappers, car accidents, plane travel and other situations that are perceived as presenting ("real") danger to their family members, or to themselves.

When alone, especially in the evening or the dark, children may report unusual perceptual experiences (i.e., seeing people peering into their room, frightening creatures reaching for them, feeling eyes staring at them). Children with this condition may be described as the demanding, intrusive and in need of a constant attention, and, as later adults, may appear quite dependant and overprotective. The individual's excessive demands often become a source of frustration for family members, leading to resentment and conflict in their family (APA, 2013).

\section{Discussion}

In the essence, any war conflict should be defined as the human's crime against humans with unpredictable consequences on those who are victims of torture, killings, injured people, or being forcefully removed from their living place and loved ones. Excessive fear concerning separation from attachment figures and living place in war-refugees is quite common as they were unprepared and being forced to move into an uncertainty. They suffer an excessive distress leaving living place or their major attachment figures (other family members, friends, relatives, employment, country, ...).

It is a sad reality of their struggling with the deep fears while anticipating their uncertain future. The level of worries is quite individual and depends on actual or anticipated danger and a risk to stay or to leave. However, it is a real persistent and excessive worry about losing major attachment figures with fear, as they stayed behind; they could be harmed or killed, injured or tortured. Related to these feelings, the refugees may feel guilty leaving family members or friends to stay, as they could be in risk of torture and/or interrogation following their relationships with those who escaped.

Alongside with worries about others left behind, the refugees are often overwhelmed by the worries and fear about their own future prospects (i.e., how they will cope in unknown host country, what will happen if they 
become ill, getting lost). Separation fear, which at times can be overpowering and greatly interfere with one's well-being, is produced by the person's inability to be comfortable; it is a pathological emotional state involving one's relationships characterised primarily by the intense needs for psychological homeostasis and proximity (Zepinic, 2022). A clue to understand this paradoxical condition may be found in one's cognitive-affective state when the person feels threatened and/or in danger - namely, the sense of vulnerability for further distress.

In this context, the trauma victim's vulnerability may be defined as a person's perception of her- himself as a subject to internal or external dangers over which her/his control is lacking or is insufficient to afford sense of safety (Beck et al., 2005). Thus, the sense of vulnerability is magnified by evident dysfunctional cognitive processes and person's underestimation of the positive aspects of one's personal resources (minimisation). The affected individual is only focused on the own weaknesses (selective abstraction) and each mistake or failure slides into an oblivion (catastrophising). Because of lost self-confidence and depleted ability in decision making, the person feels increasingly vulnerable after a particular mistake.

Due to their separation fear, the refugee children may report the fears of darkness, monsters, kidnapers, or even doctors or the Red Cross activists. Nightmare fears, resistance to going to the bed, difficulty falling asleep alone or sleeping through the night with others than with the attachment figure and complaints of having nightmares or bad dreams (even it not happened) are also very common. They may also report intrusive distressing memories of the traumatic event(s), even some dissociative reactions (i.e., flashbacks) in which they feel or act as if the traumatic event(s) were recurring.

Simple phobias which were not being reported before, overanxious disorder, sadness and/or depressed mood, behaviour problems, oppositional defiant behaviour, avoidance of people, places, or physical reminders that arouse recollections of the traumatic event(s), and child's argumentativeness are also very common signs of the children's separation fear. Separated from a major attachment figure(s), children have a persistent reluctancy or refusal to go to sleep without being near a major attachment figure or to sleep at other place than their room. Physical symptoms (i.e., headaches, muscle spasm, nausea, vomiting) are also very common in children due to the separation fear.

\section{References}

American Psychiatric Association. (2013). Diagnostic and Statistical Manual of Mental Disorders (5th ed.). Washington DC. https://doi.org/10.1176/appi.books.9780890425596

Ayalon, O. (1988). Community healing for children traumatised by war. International Journal of Psychiatry, 2 , 24-33.

Barlow, D. H. (2002). Anxiety and Its Disorders. The Guilford Press, New York.

Beck, A. T., Emery, G., \& Greenberg, R. L. (2005). Anxiety Disorders and Phobias: A Cognitive Perspective. Basic Books, New York.

Black, B. (Ed.). (1995). Separation Anxiety Disorder and Panic Disorder. (Chapter 9). In March, J.S.: Anxiety Disorders in Children and Adolescents. The Guilford Press, New York.

Bowlby, J. (1973). Attachment and loss: Vol 2. Separation: Anxiety and anger. Basic Books, New York.

Courtois, A. C., \& Ford, J. D. (2009). Treating Complex Traumatic Stress Disorder. The Guilford Press, New York.

Despotovic, T. (1997). Problem separacije u izbeglistvu (Problem of separation in the refuge). In Vlajkovic, J., Srna, J., Kondic, K. \& Popovic, M. (Eds.), Psihologija Izbeglistva (Psychology of Refuge). Nauka, Belgrade.

Duckworth, M. P., \& Follette, V. M. (2012). Retraumatization: Assessment, Treatment and Prevention. Routledge, New York. https://doi.org/10.4324/9780203866320

Falicov, G. J. (2005). Therapeutic care for refugees. Karnak, London.

Fogden, G., Barle, D., \& Steel, Z. (2020). The Impact of Family Separation and Worry About Family on Psychological Adjustment in Refugees Resettled in Australia. Journal of Traumatic Stress, 33(6), 894-907. https://doi.org/10.1002/jts.22568

Garland, C. (1998). Thinking About Trauma (Chapter 1). In Garland, C. (Ed.), Understanding Trauma. Karnak, London.

Gitelman, R., \& Klein, D. F. (1985). Childhood separation anxiety and adult agoraphobia (Chapter 4). In A. H. Tuma \& J. D. Maser (Eds.), Anxiety and the anxiety disorders. Erlbaum, Hillsdale. 
Herman, J. L. (1992). Complex PTSD: A Syndrome in Survivors of Prolonged and Repeated Trauma. Journal of Traumatic Stress, 5(3), 377-391. https://doi.org/10.1002/jts.2490050305

Horowitz, M. J. (2001). Stress Response Syndrome (4th ed.). Jason Aronson Inc., New York.

Klein, D. F., \& Rabkin, J. G. (1981). Anxiety: New research and changing concept. Raven Press, New York.

Miller, A., Hess, J. M., Bybee, D., \& Goodkind, J. R. (2018). Understanding the mental health consequences of family separation for refugees: Implications for policy and practice. American Journal of Orthopsychiatry, 88(1), 26-37. https://doi.org/10.1037/ort0000272

Myers, C. S. (1916). Contributions to the study of shell shock. The Lancet, 187(4819), 65-69.

Shear, K., Yin, R., Ruscio, A. M. et al. (2006). Prevalence and correlates of estimated DSM-IV child and adult separation anxiety disorder in the National Comorbidity Survey Replication. American Journal of Psychiatry, 163(6), 1074-1083. https://doi.org/10.1176/ajp.2006.163.6.1074

Simic, M., \& Srna, J. (1997). Psiholoska pomoc porodici u izbeglistvu (Psychological support to family in the refuge). In Vlajkovic, J., Srna., Kondic, K. \& Popovic, M. (Eds.), Psichologija Izbeglistva (Psychology of Refuge). Nauka, Belgrade.

Van der Kolk, B. A., McFarlane, A. C., \& Weiseath, L. (1996). Traumatic Stress. The Guilford Press, New York.

Whetten, K., Osterman, J., Whetten, R., \& O’Donnell, K. (2011). More Than the Loss of a Parent: Potentially Traumatic Events Among Orphaned and Abandoned Children. Journal of Traumatic Stress, 24(2), 174-182. https://doi.org/10.1002/jts.20625

Wilson, J. P. (2006). The Posttraumatic Self. Routledge, New York. https://doi.org/10.4324/9780203955932

World Health Organisation. (2018). International Statistical Classification of Disease and Related Health Problems (ICD-11). Geneva.

Zepinic, V. (1997). Psychosocial characteristics of war-related posttraumatic stress disorder (Chapter 10). In Ferguson, B. \& Barnes, D. (Eds.), Perspectives on Transcultural Mental Health. TCMHC, Sydney.

Zepinic, V. (2010). Defining a war-related psychological trauma: Is that one impossible task? International Journal of Medicine, 3, 376-383.

Zepinic, V. (2011). Hidden Scars: Understanding and Treating Complex Trauma. Xlibris Publishing, London.

Zepinic, V. (2015). Persistence of "Survival Skills" as a Risk Factor for Suicide in Severely Traumatised Individuals. International Journal of Emergency Mental Health and Human Resilience, 17(2), 552-558. https://doi.org/10.4172/1522-4821.1000214

Zepinic, V. (2016). Disintegration of the Self-Structure Caused by Severe Trauma. Psychology and Behavioural Sciences, 5(4), 83-92. https://doi.org/10.11648/j.pbs.20160504.12

Zepinic, V. (2018). Four-Phased Dynamic Therapy Model in Treating Trauma-Induced Dissociation. Psychology, 9, 1979-2010. https://doi.org/10.4236/psych.2018.98114

Zepinic, V. (2019). The Self and Complex Trauma (2nd ed.). Austin Macauley Publishing, London, UK.

Zepinic, V. (2021). Forensic Notion of the Trauma-Related Dissociation. Beijing Law Review, 12, 948-972. https://doi.org/10.4236/blr.2021.123049

Zepinic, V. (2022). Complex Trauma Syndrome. Austin Macauley Publishing, London, UK.

Zlotnick, C., Warshaw, M., Shea, M. T., Allsworth, J., Pearlstein, T., \& Keller, M. B. (1999). Chronicity in posttraumatic stress disorder (PTSD) and predictors of course of comorbid PTSD in patients with anxiety disorders. Journal of Traumatic Stress, 12, 89-100. https://doi.org/10.1023/A:1024746316245

\section{Copyrights}

Copyright for this article is retained by the author(s), with first publication rights granted to the journal.

This is an open-access article distributed under the terms and conditions of the Creative Commons Attribution license (http://creativecommons.org/licenses/by/4.0/). 